lines. HIMA has objected to the proposal on the basis that manufacturers' oversight of physicians' use of their products is inappropriate; because the proposed requirements would require lengthy and expensive testing of single-use products that ESRD facilities are reprocessing; because the FDA's current workload delays approvals for 400 days, and the addition of new applications for already-approved dialyzers would significantly lengthen the delay for all devices; and because the FDA may not have the authority to force compliance with the guidelines.

FROM: AAMI News February 1994.

\section{Penicillin Tolerated by Majority of Patients with History of Allergy}

Dr. Gadde and colleagues in Baltimore found that 97\% of study patients with a history of penicillin allergy and negative skin tests were able to tolerate treatment with penicillin. In a 5-year surveillance program for penicillin allergies in an STD clinic, 8.3\% of the 9,313 subjects enrolled reported a previous adverse reaction to penicillin. These reactions varied from anaphylaxis, urticaria, or exanthematous rashes to uncertain histories. All subjects with histories of penicillin allergy were skin-tested, and approximately $50 \%$ of the subjects without this history also were skin-tested. Penicillin skin-testing was performed in duplicate with benzyl penicilloyl polylysine (PPL), which is the major determinant, and a minor determinant mixture (MDM). Subjects who were positive to the MDM also were skin-tested with its individual constituents. All subjects with negative skin tests in both groups were treated with penicillin.

Of the 776 history-positive subjects who were skin tested, $7.1 \%$ reacted to either PPL or MDM or both, and $2.7 \%$ had equivocal reactions. Of the 4,287 subjects without a history of penicillin allergy who were skin-tested, significantly fewer $(1.7 \%)$ had positive reactions and $0.3 \%$ had equivocal reactions. Of all the subjects with positive skin tests, $75 \%$ reacted to PPL alone, $10.2 \%$ to MDM alone, and $14.8 \%$ to both PPL and MDM. Of the subjects with equivocal reactions, $82 \%$ were retested later, and all were found to have negative skin tests.

The reactions were classified according to the type of prior reaction. Positive skin tests occurred in $17.3 \%$ of patients with a history of anaphylaxis, $12.4 \%$ of patients with a history of urticaria, $4 \%$ of patients with a history of exanthematous rash, and $1.7 \%$ of patients with an uncertain history.

This study confirms the need for penicillin skin testing to verify or exclude the diagnosis of penicillin allergy

FROM: Gadde J, et al. JAMA 1993;270:2456-2463. 


\section{INFECTION CONTROL AND
HOSPITAL EPIDEMIOLOGY}

\section{The Society for Hospital Epidemiology of America (SHEA) and SLACK Inc. Copyright and Republication Policy}

The Society for Hospital Epidemiology of America (SHEA) and SLACK Inc. hold copyright on Infection Control and Hospital Epidemiology. We request that all authors of works transfer to SHEA and SLACK Inc. all rights, title, and interest to such works, including copyright. In accord with the Copyright Act of 1976, we must acquire every author's signature to effect the transfer. A written work cannot be considered for publication until the "Assignment of Copyright" form is signed by the author or authors and is on file at the editorial offices. Please submit this signed form with your manuscript. In the event that a manuscript is not accepted for publication, this agreement will be returned to the authors.

Signed "Assignment of Copyright" forms confirm that a work submitted has not previously been published, is not subject to copyright or other rights except those of the author to be transferred to SHEA and SLACK Inc., and is not under consideration for publication elsewhere, except under circumstances communicated in writing at the time the work is submitted.

Permission to reproduce any part of the works published by SHEA and SLACK Inc. in Infection Control and Hospital Epidemiology in any form or by any means, electronic or mechanical, is not permitted without written permission from SLACK Inc.

\section{Assignment of Copyright}

In consideration of SLACK Incorporated and The Society for Hospital Epidemiology of America (collectively called the "Publisher") in publishing my (our) submitted manuscript, the undersigned hereby transfer(s), assign(s), and otherwise convey(s) all copyright in the manuscript to the Publisher. The undersigned declares that the manuscript is original and, to the best of the undersigned's knowledge, contains no matter that is libelous or unlawful or that infringes upon anyone else's rights of copyright.

In addition, we affirm that the work is the work of every author listed and is not under consideration for publication elsewhere, except under circumstances communicated to the Publisher in writing at the time the work is submitted.

MANUSCRIPT NUMBer (if known)

DATE

AUTHORs

TITLE

\section{All Authors}

Signature

Date

Signature

Date

Signature

Date

Signature

Date

Signature

Date

Signature

Date

Signature

Date

This form mav he ohotornnied 


\section{Information for Authors}

Manuscripts should consist of new material based on hospital epidemiologic or infection control activities, from the United States or abroad. The Journal welcomes submissions that involve the use of epidemiologic principles and methods to evaluate or improve the delivery of care within healthcare institutions or that address the transmission of infection. Examples of appropriate material include rates, distributions, preventive measures, or cost benefit studies of infections or other adverse events in patients: surveillance; occupational health issues affecting healthcare workers; pertinent regulatory actions; and analyses of resource utilization.

Manuscripts should be accompanied by a cover letter that includes the title of the manuscript and the name, address, telephone, and (if available) fax number of the corresponding author. If blinded review is desired, the cover letter should so request. All manuscripts should be submitted in triplicate (with three copies of figures and tables), typewritten on one side of $81 / 2 \times$ 11-inch paper, double-spaced, and with generous margins. Pages should be numbered consecutively beginning with the title page. The author should keep a complete copy of the manuscript, as submitted manuscripts will not normally be returned (however, original figures, photographs, or other artwork will always be returned).

The organization of the paper should be as follows: title page; abstract; introduction: methods; results; discussion: acknowledgments; references; tables: figures; and figure legends. The main sections and subdivisions should be indicated by side headlines flush with the left margin and two lines above the text. The Arabic numbering system should be used.

\section{CLINICAL TRIALS}

The Editor requests that authors reporting the results of clinical trials describe clearly the following: 1) eligibility criteria; 2) whether or not subjects were admitted before allocation to one of the study groups: 3) the method of randomization; 4) whether the study was "masked," what specific information was masked and whether subjects. clinicians, and evaluators were all masked; 5) the method used to identify treatment complications; 6) an explanation and analysis of subjects lost to follow-up; 7) statistical methods employed; 8) information that led to the determination of the size of the study groups and the expected differences between groups; and 9) indications that studies involving human subjects have been reviewed and approved by their institutional review board.

\section{RAPID PUBLICATION}

A request for rapid publication must be stated in the cover letter, and manuscripts should not exceed ten double-spaced, typewritten pages. The Editor will send the manuscript for rapid review only if the information contained is a unique, scholarly contribution of special importance. Such papers will be published within three to four months of acceptance. No comments will accompany rejected papers, but manuscripts may be resubmitted under the normal publication procedure.

\section{READERS FORUM}

Brief communications are encouraged of approximately four to six typewritten pages containing information that does not represent a formal study. They may summarize unusual experiences or reflect opinions, hypotheses, or impressions related to infection control or hospital epidemiology.

\section{TITLE PAGE}

A separate title page should include the following: title of manuscript; author(s): laboratory or institution of origin with city and state: acknowledgment of grant support; name. address, and telephone number of the corresponding author; and (if different) address to be used for reprint requests. An abbreviated title, to be used as a running head, should be included. This should not exceed four words. A preliminary report or abstract should be credited by use of a footnote to the title. Provide three to six key words (MESH terms are preferred) appropriate for indexing the manuscript. If blinded review was requested, include a second title page that contains only the full and abbreviated titles.

\section{ABSTRACT}

Authors submitting manuscripts reporting the results of clinical investigations should prepare an abstract of no more than 250 words under the following headings: Objective, Design, Setting, Patients (or Participants), Interventions (if any), Results, and Conclusions. The content following each heading should be as follows:

1. Objective

The abstract should begin with a clear statement of the precise objective or question addressed in the report. If more than one objective is addressed, the main objective should be indicated and only key secondary objectives stated. If an a priori hypothesis was tested, it should be stated.

2. Design

The basic design of the study should be described. The duration of follow-up, if any, should be stated. As many of the following terms as apply should be used.

a. Intervention studies: randomized control trial; nonrandomized control trial; double-blind; placebo control; crossover trial; before/after trial.

b. For studies of screening and diagnostic tests: criterion standard (ie, a widely accepted standard with which a new or alternative test is being compared; this term is preferred to "gold standard"); blinded or masked comparison

c. For studies of prognosis: inception cohort (subjects assembled at a similar and early time in the course of the disorder and followed thereafter); cohort (subjects followed forward in time, but not necessarily from a common starting point): validation cohort or validation sample if the study involves the modeling of clinical predictions.

d. For studies of causation: randomized control trial; cohort; case-control; survey (preferred to "cross-sectional study").

e. For descriptions of the clinical features of medical disorders: survey; case series.

f. For studies that include a formal economic evaluation: costeffectiveness analysis; cost-utility analysis; cost-benefit analysis. For new analyses of existing data sets, the data set should be named and the basic study design disclosed.

3. Setting

To assist readers in determining the applicability of the report to their own clinical circumstances, the study setting(s) should be described. Of particular importance is whether the setting is the general community, a primary care or referral center, private or institutional practice, ambulatory, or hospitalized care.

4. Patients or Other Participants

The clinical disorders, important eligibility criteria, and key sociodemographic features of patients and how they were selected should be provided, including the number of otherwise eligible subjects who were approached but refused. If matching is used for comparison groups. characteristics that are matched should be specified. In follow-up studies, the proportion of participants who completed the study must be indicated. In intervention studies, the number of patients withdrawn for adverse effects should be given.

For selection procedures, these terms should be used, if appropriate: random sample (here "random" refers to a formal, randomized selection in which all eligible subjects have a fixed and usually equal chance of selection); population-based sample; referred sample; consecutive sample; volunteer sample; convenience sample. These terms assist the reader to determine an important element of the generalizability of the study. They also supplement (rather than duplicate) the terms used by professional indexers when articles are entered into computerized databases.

5. Intervention $(\mathrm{s})$

The essential features of any interventions should be described, including their method and duration of administration. The intervention should be named by its most common clinical name (eg, the generic term "chlorthalidone"). Common synonyms should be given as well to facilitate electronic textword searching. This would include the brand name of a drug, if a specific product was studied.

6. Results

The main results of the study should be given. Measurements that require explanation for the expected audience of the article should be defined. Important measurements not included in the presentation of results should be declared. As relevant, it should be indicated whether observers were blinded to patient grouping, particularly for subjective measurements. Due to the current limitations of retrieval from electronic databases, results must be given in narrative or point form rather than tabular form. If possible, the results should be accompanied by confidence intervals (eg, 
$95 \%$ ) and the exact level of statistical significance. For comparative studies, confidence intervals should relate to the differences between groups. For nonsignificant differences for the major study outcome measure(s), the clinically important difference sought should be stated and the confidence interval for the difference between the groups should be given. When risk changes or effect sizes are given, absolute values should be indicated so that the reader can determine the absolute as well as relative impact of the finding. Approaches such as "number needed to treat" to achieve a unit of benefit are encouraged when appropriate; reporting of relative differences alone is usually inappropriate. If appropriate, studies of screening and diagnostic tests should use the terms sensitivity, specificity and likelihood ratio. If predictive values or accuracy are given, prevalence or pretest likelihood should be given as well. No data should be reported in the abstract that do not appear in the rest of the article.

7. Conclusion(s)

Only those conclusions of the study that are directly supported by the evidence reported should be given, along with the clinical application (avoiding speculation and over-generalization); indicate whether additional study is required before the information should be used in normal clinical settings. Equal emphasis must be given to positive and negative findings of equal scientific merit.

To permit quick and selective scanning, the headlines outlined above should be included in the abstract. For brevity, parts of the abstract can be written in phrases rather than complete sentences (eg, 2. Design. Double blind randomized trial. rather than 2. Design. The study was conducted as a double-blind, randomized trial.) This technique may make reading less smooth but facilitates selection scanning and allows more information to be conveyed per unit of space.

TABLES

Tables should be double-spaced, each on a separate page, and self-contained. Do not use vertical lines or ditto marks. The table number should be typed flush left, with the table title beneath it. Symbols for footnotes are listed below Abbreviations used in a table should be explained at the bottom of the table after the footnotes.

\section{FIGURES}

Three sets of unmounted glossy prints should be enclosed in separate envelopes. Indicate lightly on the back margin of each figure the number. name of author, and top.

\section{PHOTOGRAPHS}

Three copies of each photograph should be submitted. Any identifiable human subject must sign a release form before the photograph can be used Radiographs and other black-and-white material should be submitted as unmounted glossy prints; $5 \times 7$-inch size is preferred. A separate identification label should be pasted on each print: do not write directly on the print or use paper clips or staples. Photomicrographs or other color materials should be submitted as color transparencies. Any charges for separation of color photographs, as indicated by the Editor, shall be billed to the author. Actual magnification and staining method should be given where appropriate; electron photomicrographs should have internal scale markers.

\section{LEGENDS}

Legends should be double-spaced on a separate page.

\section{REFERENCES}

References should be double-spaced and should be cited consecutively in the text with superscript numbers outside punctuation. A reference to a paper "in press" may be included. Citations such as "in preparation," "submitted for publication," "unpublished data," and "personal communication" should be given in parentheses in the text only. At the end of each article, references should be listed in the numerical order in which they appear in the text. The names of all authors should be given unless there are more than six, in which case the names of the first three authors are used, followed by "et al." Abbreviations of the names of the journals should conform to Index Medicus. Journal titles should be cited as they existed at the time of publication. Unlisted journals should not be abbreviated. Authors are responsible for bibliographic accuracy.

1. Articles

Annuniziato D, Goldblum LM. Staphylococcal scalded skin syndrome: a complication of circumcision. A m J D is Child. 1978;132:1187- 1188.

2. Books

Heoprich PD. Infectious Diseases. 2nd ed. New York, NY Harper \& Row Pubs Inc; 1977:169.

3. Contributions to Books

Schaffner W. Psittacosis: ornithosis, parrot fever. In: Beeson PB, McDermott W, Wyngaarden JB. eds. Cecil Textbook of M edicine. 15th ed. Philadelphia, Pa: WB Saunders Co; 1979336338.

\section{FOOTNOTES}

Footnotes to the text and tables should be as few as possible. Each should be typed at the foot of the appropriate page, separated from the text or table by a horizontal line. Designate footnotes by the following symbols in this order:

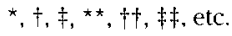

\section{ABBREVIATIONS AND NOMENCLATURE}

Abbreviations should conform to the Chicago Manual of Style published by The University of Chicago Press, Chicago, Illinois. Abbreviations should be kept to a minimum, preferably confuted to the tables. Symbols for units of measurement $(\mathrm{mm}, \mathrm{ml})$ should not be followed by periods. Chemical or generic names of drugs are preferred. A proprietary name may be given only after it is preceded by the chemical name the first time it appears. Proprietary names must be followed by the manufacturer, city, and state of location. Unfamiliar terms and abbreviations must be defined when first used.

\section{REVIEW PROCESS}

Each manuscript will be reviewed by the Editor and at least one other Editorial Board member. Authors will be notified as soon as possible regarding the acceptability of their manuscripts. See "Infection Control and Hospital Epidemiology: The Formal Review Process (1991;12[1]:11-13) for more information regarding the review process.

\section{PAGE PROOFS}

Page proofs will be sent to the author for approval before being printed.

\section{REPRINTS}

The senior author will be sent five complimentary copies of the issue in which the article appears. An order form listing reprint prices will be included with complimentary copies of the issue.

\section{SUBMISSIONS}

Mail manuscripts to:

\section{Michael D. Decker, MD, MPH, Editor}

Infection Control and Hospital Epidemiology

Vanderbilt University School of Medicine

A-1131 Medical Center North

Nashville, TN 37232-2637

(615) 343-1095 


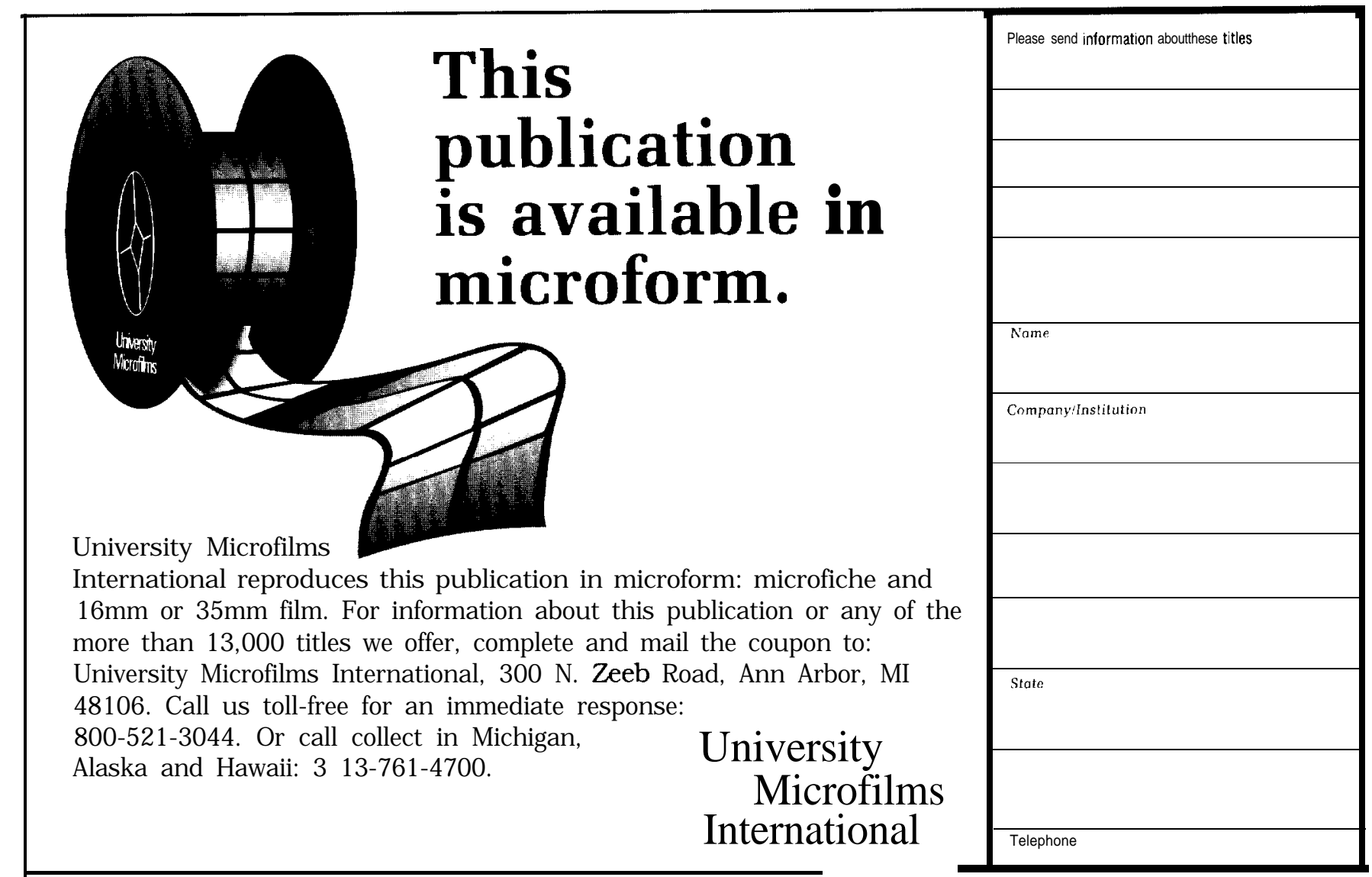

\section{Classified Marketplace}

re•sponse \ri-`spän(t)s \}

That's what you want from a classified ad. And Classified Marketplace lets you reach the audience you want-cost effectively-to get you the response you need.

- Employment Opportunities

- Positions Wanted

- Meetings

- Services
- Educational Opportunities

- For Sale/For Rent

- Miscellaneous

- Wanted

\section{RATES}

Typesetting Available

Line Advertising - \$23 per line,

$\$ 138$ minimum

Classified advertising is non-commissionable

Contact our Classified Advertising Representative for help in placing your customized ad message:

Call toll-free

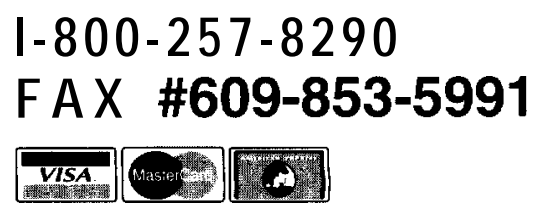

or send typed copy to:

INFECTION CONTROL AND HOSPITAL EPIDEMIOLOGY
Donna Coles 6900 Grove Road

Thorofare, NJ 08086-9447 